\title{
New methodology for urban seismic risk assessment from a holistic perspective
}

\author{
Martha L. Carreño • Omar D. Cardona • \\ Alex H. Barbat
}

Received: 9 February 2011 / Accepted: 5 July 2011 / Published online: 19 July 2011

(C) Springer Science+Business Media B.V. 2011

\begin{abstract}
The seismic risk evaluation usually works with a fragmented concept of risk, which depends on the scientific discipline in charge of the assessment. To achieve an effective performance of the risk management, it is necessary to define risk as the potential economic, social and environmental consequences due to a hazardous phenomenon in a period of time. This article presents a methodology which evaluates the seismic risk from a holistic perspective, which means, it takes into account the expected physical damage and also the conditions related to social fragility and lack of resilience, which favour the second order effects when a hazard event strikes an urban centre. This seeks to obtain results which are useful in the decision making process for risk reduction. The proposed method for urban seismic risk evaluation uses the fuzzy sets theory in order to handle qualitative concepts and variables involved in the assessment, the physical risk level and aggravation level, related to the social fragility and the lack of resilience, are evaluated and finally a total risk level is determinate.
\end{abstract}

Keywords Holistic approach · Risk evaluation · Seismic risk · Urban risk ·

Socio-economic vulnerability · Fuzzy sets

\section{Introduction}

For management purposes, risk can be defined as the potential economic, social and environmental consequences of hazardous events that may occur in a specified period of time. However, in the past, in many cases the concept of risk has been defined in a fragmentary way,

M. L. Carreño $(\varangle)$ · A. H. Barbat

Centre Internacional de Mètodes Numèrics en Enginyeria (CIMNE), Barcelona, Spain

e-mail: liliana@cimne.upc.edu

O. D. Cardona

Universidad Nacional de Colombia, Manizales, Colombia

M. L. Carreño $\cdot$ A. H. Barbat

Technical University of Catalonia, Barcelona, Spain 
according to each scientific discipline involved in its appraisal (Cardona 2004). Based on the formulation of the disaster risk of UNDRO (1980) several methodologies for risk assessment have been developed from different perspectives in the last decades. From a holistic perspective, risk requires a multidisciplinary evaluation that takes into account not only the expected physical damage, the number and type of casualties or economic losses (first order impact), but also the conditions related to social fragility and lack of resilience conditions, which favour the second order effects (indirect impact) when a seismic hazard event strikes an urban centre (Cardona and Hurtado 2000; Masure 2003; Carreño et al. 2007a,b).

It has been common to measure risk solely in physical terms given that social vulnerability is difficult to evaluate quantitatively. This does not imply, however, that it is not feasible to analyze vulnerability in relative terms or by means of indicators and indices, thus allowing a vision of "relative risk" which permits decisions to be made and priorities established as regards prevention and mitigation. Risk indices should take into account the physical aspects of risk as well as the non-physical aspects, which include the economic capacity of the community, the ability of the population to self protect, the social structure and its organizational levels, governance, amongst others (Cardona et al. 2003).

There are a wide range of approaches for integrating data and modelling risk and vulnerability. Approaches based on fuzzy logic and expert systems, however, can enable quantitative values to be assigned.

A multidisciplinary estimation of risk to guide the decision making, that takes into account not only geophysical and structural aspects, but also economic, social, institutional variables, among others, is considered herein as a holistic approach, which can be also denominated integral, involving all th the urban scenarios sential, because the buildings and infrast The holistic approach for risk estimation may generate certain controversy when it is seen for free at https//www.scipedia.com to download the.version without the watermark to the correct formulation of the problem is preferable, rather than an exact response to the incorrect formulation of the problem. The level of ambiguity associated with the holistic approach is preferable to the approach of a single point of view that is usually associated to greater precision (Cardona 2001).

In summary, although reductionist and holistic approaches may both be valuable, here the latter is preferred over the former because the objective of the analyses is to promote a comprehensive risk management. In other words, it is necessary to consider not only the physical vulnerability but also the other vulnerabilities throughout urban planning, education, emergency preparedness, and so on.

Cardona (2001) developed a conceptual framework and a model for risk analysis of a city from a holistic perspective, describing seismic risk by means of indices. He considered both "hard" and "soft" risk variables of the urban centre, taking into account exposure, socio-economic characteristics of the different areas or neighborhoods of the city and their disaster coping capacity or degree of resilience. One of the objectives of this model was to guide the decision-making in risk management, helping to identify the critical zones of the city and their vulnerability from the perspective of different professional disciplines. This method base its evaluation on a relative normalization of the involved indicators.

Carreño (2006) developed an alternative method for Urban Risk Evaluation, starting from Cardona's model (Cardona 2001; Barbat and Cardona 2003), in which urban risk was evaluated also using composite indicators or indices but in a different way. Expected building 
damage and losses in the infrastructure, obtained from loss scenarios, were used as the basic information for the evaluation of a physical risk index in each unit of analysis (Carreño et al. 2007a). In addition, this method improves the procedure of normalization and calculates the final risk indices in an absolute (non relative) manner. This feature facilitates the comparison of risk among urban centers. The exposure and the seismic hazard were eliminated in the evaluation method because they are included into the calculation of the physical risk variables. The descriptor of population density, which in Cardona's model was included as a component of the exposure, is now a descriptor of social fragility. This new approach preserves the use of indicators and fuzzy sets or membership functions, proposed originally by Cardona (2001), but in a different way. Other improvements of the proposed model refer to the units of some of the descriptors; in certain cases it is more important to normalize the input values respecting the population than with respect to the area of the studied area (Carreño et al. 2007a). Afterwards, Marulanda et al. (2009) evaluate the robustness of the methodology proposed by Carreño (2006) and (Carreño et al. 2007a).

As a new alternative, this paper proposes an additional method which uses the fuzzy sets theory in order to provide a more fexible tool in cases where the information is not available or incomplete but which preserves the conceptual framework of the previous methodologies.

Figure 1 shows the conceptual framework of the holistic approach for risk evaluation. From this comprehensive perspective, it can be seen that risk is a function of the physical vulnerability — or the potential physical damage — and a set of vulnerability factors $\varepsilon_{i}$ that configure the vulnerability conditions of the context. The physical vulnerability is obtained from the susceptibility of the exposed elements to hazards, considering the potential intensities, I, of the hazardo on the social fragilitie echnical system or cont ystem dynamics to reduce risk, it is necessar

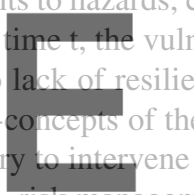
$\mathrm{D} \mid \mathrm{A}$

tive actions the vulnerability factors $\varepsilon_{i}$. Then, risk management requires a system of control

\section{Holistic evaluation of risk based on indices}

In the holistic evaluation of risk using indices risk results are achieved aggravating the physical risk by means of the contextual conditions, such as the socio-economic fragility and the lack of resilience. Input data about these conditions at urban level are necessary to apply the method. This approach contributes to the effectiveness of risk management, inviting to the action through the identification of weaknesses of the urban centre.

The socio-economic fragility and the lack of resilience are described by a set of indicators (related to indirect or intangible effects) that aggravate the physical risk (potential direct effects). Thus, the total risk depends on the direct effect, or physical risk, and the indirect effects expressed as a factor of the direct effects. Therefore, the total risk is expressed as follows:

$$
R_{T}=R_{F}(1+F)
$$

equation known as the Moncho's Equation in the field of disaster risk indicators, where $R_{T}$ is the total risk index, $R_{F}$ is the physical risk index and $F$ is the aggravating coefficient. This coefficient depends on the weighted sum of a set of aggravating factors related to the 


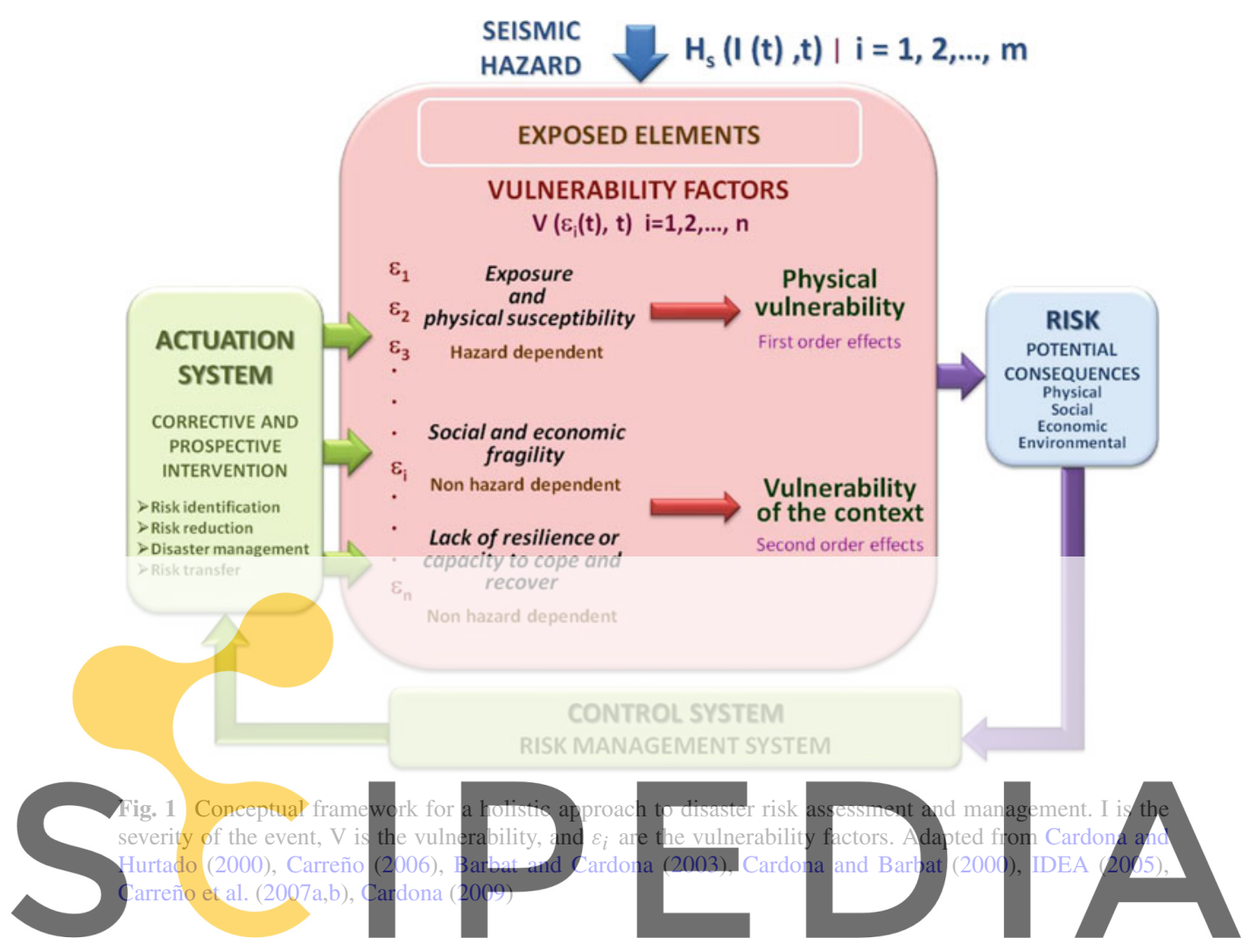

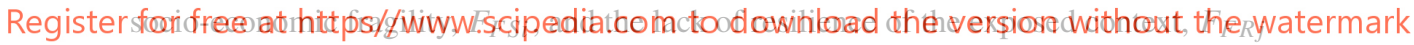

$$
F=\sum_{i=1}^{m} w_{F S i} F_{F S i}+\sum_{j=1}^{m} w_{F R j} F_{F R j}
$$

where $w_{F S i}$ and $w_{F R j}$ are the weights or influences of each $i$ and $j$ factors and $m$ and $n$ are the total number of descriptors for social fragility and lack of resilience, respectively. The aggravating factors $F_{F S i}$ and $F_{F R j}$ are calculated using transformation functions, which are discussed in the following.

The descriptors used in this evaluation have different nature and units, the transformation functions standardize the gross values of the descriptors, transforming them into commensurable factors. Figure 2 shows a model for the transformation functions used by the methodology in order to calculate the risk and aggravating factors. They are membership functions for high level of risk and high aggravating level for each. In the Fig. 2, the $x$-axis are values of the descriptors while the value of the factor (physical risk or aggravation) is in the $y$-axis, taking values between 0 and 1 , were 0 is the non membership and 1 is the total membership. The limit values, $X_{\min }$ and $X_{\max }$, are defined taking into account the expert opinions and information about past disasters. In the case of the descriptors of lack of resilience, the function has the inverse shape; the higher value of the indicator gives lower value of aggravation. Figure 3 shows examples of the transformation functions used. The weights $w_{F S i}$ and $w_{F R j}$ represent the relative importance of each factor and are calculated by means of the Analytic Hierarchy 


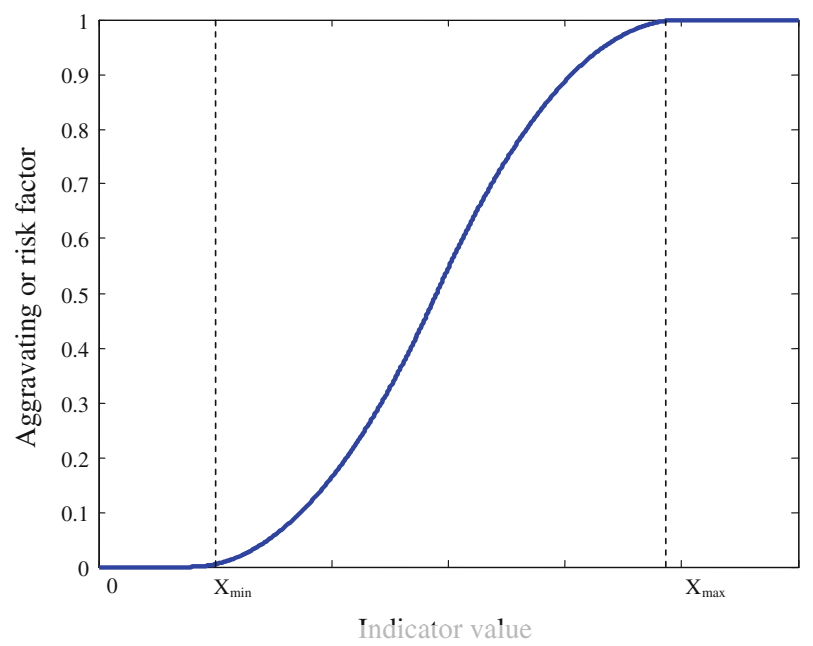

Fig. 2 Model of the transformation functions
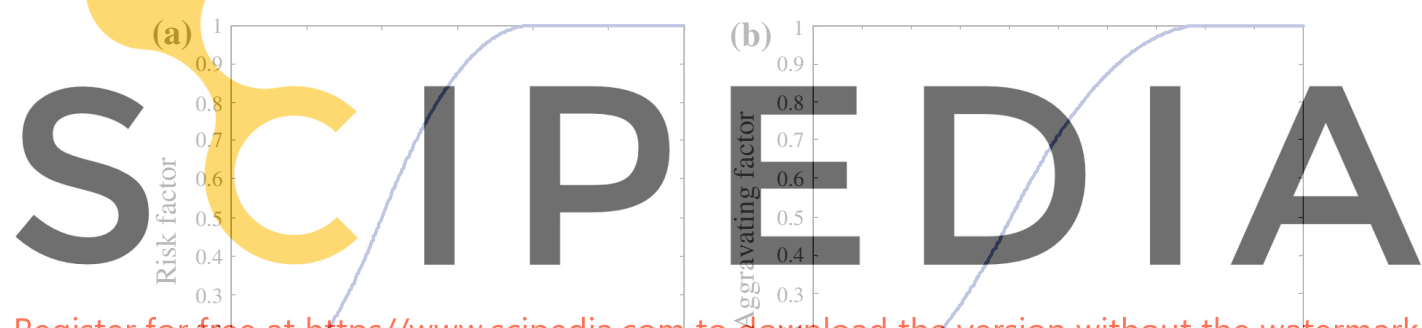

50.3

Register for free at https//www.scipedia.com to download the version without the watermark



(\% Damaged area / Total area)

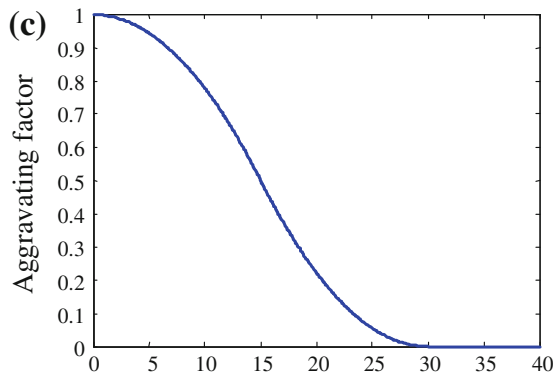

Hospital beds (\# hospital beds each 1000 inhabitants) P[0 30]

Fig. 3 Examples of transformation functions: a damaged area; $\mathbf{b}$ mortality rate; and $\mathbf{c}$ hospital beds 


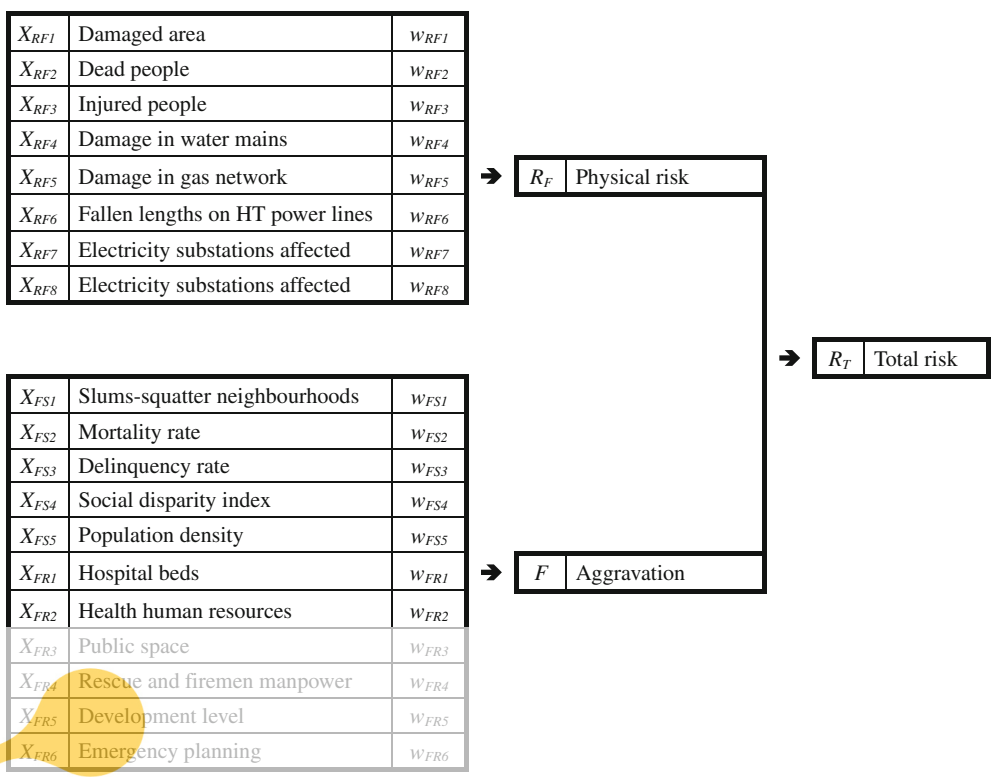

Fig. 4 Descriptors of the physical risk, social fragility and lack of resilience and their weights
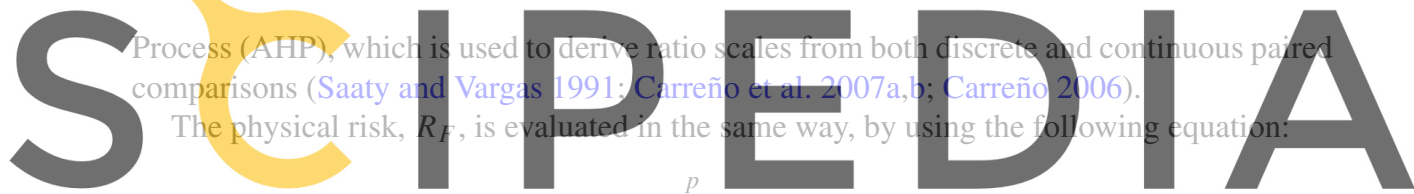

$R_{F}=\sum w_{R F i} F_{R F i}$

(3)

Register for free at https//www.scipedia.comto download the version without the watermark

Figure 4 shows the process of calculation of the total risk index for the units of analysis, which could be districts, municipalities, communes or localities, starting from the descriptors of physical risk, $X_{R F i}$, and the descriptors of the aggravating coefficient $F$, that is, $X_{F S i}$ and $X_{R F i}$, using the weights $w_{R F i}, w_{F S i}$ and $w_{F R i}$ of each descriptor. Figure 4 also shows the descriptors used to describe the physical risk, the social fragility and the lack of resilience for an urban centre. These descriptors were choose as the most significant for each category, notwithstanding they can be changed by others according to the available information for each case study. The robustness of this methodology has been also studied assessing the uncertainty of values and sensitivity to change of values, weights and transformation functions (Marulanda et al. 2009). Detailed information about this evaluation method can be founded in references (Carreño et al. 2007a; Carreño 2006; Barbat et al. 2011). For management purposes, the risk assessment should to improve the decision-making process in order to contribute to the effectiveness of risk management, calling for action and identifying the weaknesses of the exposed elements and their evolution over time (Carreño et al. 2007b).

\section{The new holistic evaluation of risk by using fuzzy sets}

This alternative method uses fuzzy sets instead the indices or crisp indicators used by the method based on indices. The main objective of this new approach is to measure seismic 
risk from an integrated and comprehensive perspective and to guide decision-making identifying the main multidisciplinary factors of vulnerability to be reduced or intervened but using expert opinions when the data is not available or incomplete. The variables and steps of the methodology are similar to those of the original method (Fig. 4): the potential physical damage is result of the convolution of the seismic hazard and the physical vulnerability of buildings and infrastructure and the aggravating coefficient is obtained from the social context conditions. However, the difference of this holistic evaluation method is the use of linguistic variables in the process of qualification of the input variables (descriptors) which reflect the physical risk and the aggravating conditions. Using qualifications as very low, low, medium, high and very high the descriptors obtained from the loss scenarios and from socio-economic and coping capacity information of the exposed context are assess in order to calculate the total risk in the city.

The weights used, as in the original method, take values also according to the expert opinions for each studied city and by applying the Analytic Hierarchical Process (AHP) (Saaty and Vargas 1991; Carreño et al. 2007a,b).

The qualification for each descriptor is obtained by means of fuzzy sets ( $L_{R F i}$ or $L_{F i}$ ). Membership functions for the five levels of physical risk and aggravation are defined for each descriptor based on expert opinion. Figure 5 shows the membership functions for the fuzzy sets corresponding to the predefined physical risk levels of the damaged area. Using this type of functions, a physical risk index and qualification is obtained by means of the union and subsequent defuzzification, applying the method of the centroid of area (COA) of the group of descriptors
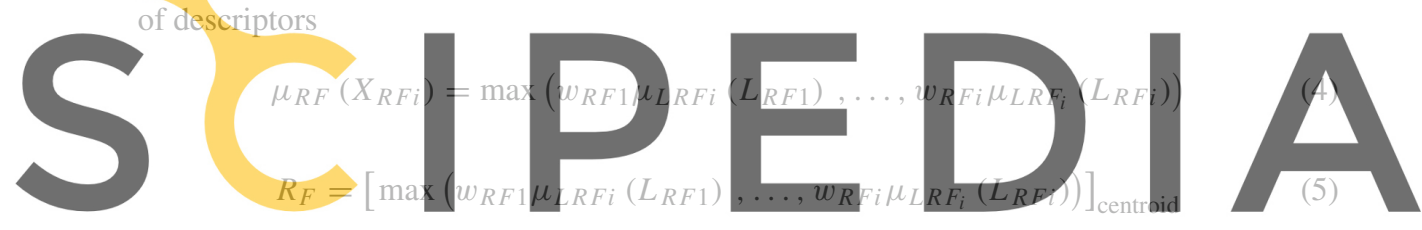

Register for free at https//WwW.scipedia.com to download the version without the watermark

$$
\mu_{F}\left(X_{F S i}, X_{F R i}\right)=\max \left(w_{F S i} \mu_{L F 1}\left(L_{F i}\right), \ldots, w_{F R i} \mu_{L F_{i}}\left(L_{F i}\right)\right)
$$

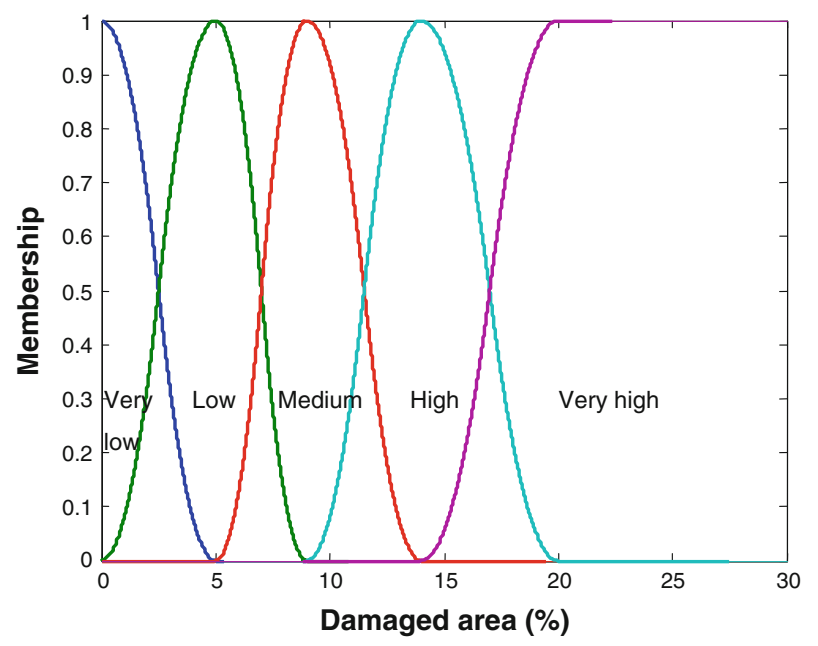

Fig. 5 Membership functions for physical risk levels by damaged area 




10000 inhabitants)

Fig. 6 Membership functions for different aggravation levels by mortality rate
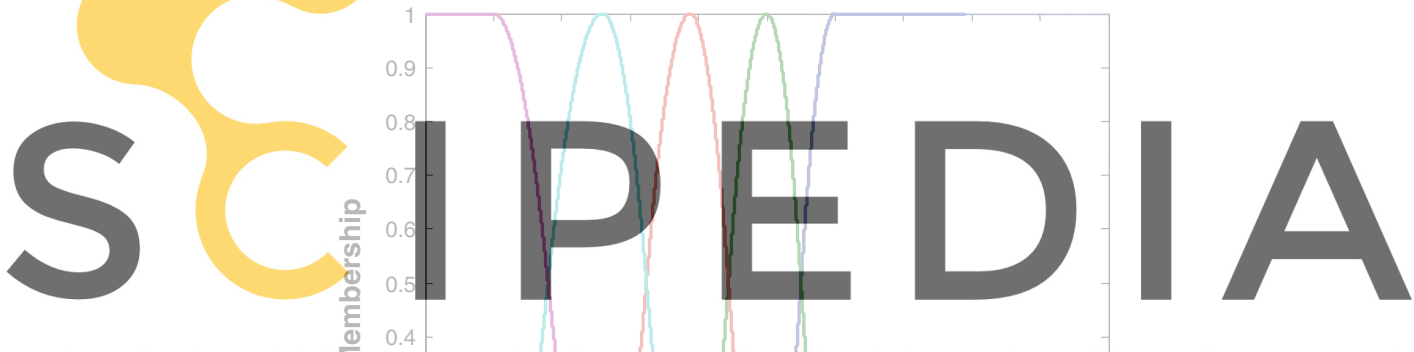

Register for free at http̄s//www.scipedia.com to download the version without the watermark

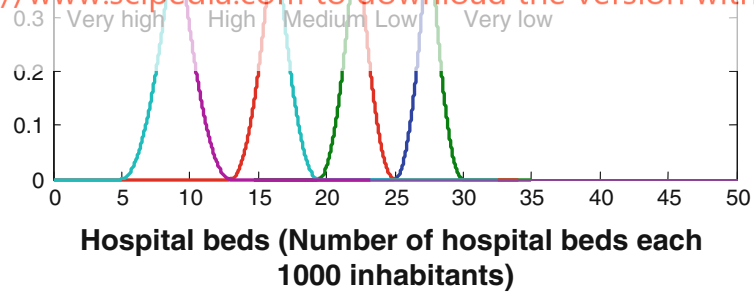

Fig. 7 Membership functions for the aggravation levels by hospital beds

$$
F=\left[\max \left(w_{F S i} \mu_{L F 1}\left(L_{F 1}\right), \ldots, w_{F R i} \mu_{L F i}\left(L_{F i}\right)\right)\right]_{\mathrm{centroid}}
$$

Figures 6 and 7 show examples of the membership functions used for the social fragility and lack of resilience descriptors corresponding to the aggravation level of mortality rate and hospital beds.

Finally, the total risk is calculated applying a fuzzy rule base to the obtained qualifications of physical risk and aggravation. The levels are identified as linguistic variables: low, medium-low, medium-high, high and very high. The used fuzzy rule base is shown in Table 1.

The Figs. 8 and 9 show the membership functions used for the levels of risk and aggravation. 
Table 1 Fuzzy rule base used to evaluate the Total Risk

\begin{tabular}{llllll}
\hline Aggravation & Low & Medium-low & Medium-high & High & Very high \\
\hline Physical risk & & & & & \\
Low & Low & Low & Medium-low & Medium-low & Medium-low \\
Medium-low & Medium-low & Medium-low & Medium-high & Medium-high & Medium-high \\
Medium-high & Medium-high & Medium-high & High & High & Very high \\
High & High & High & Very high & Very high & Very high \\
Very high & Very high & Very high & Very high & Very high & Very high \\
\hline
\end{tabular}

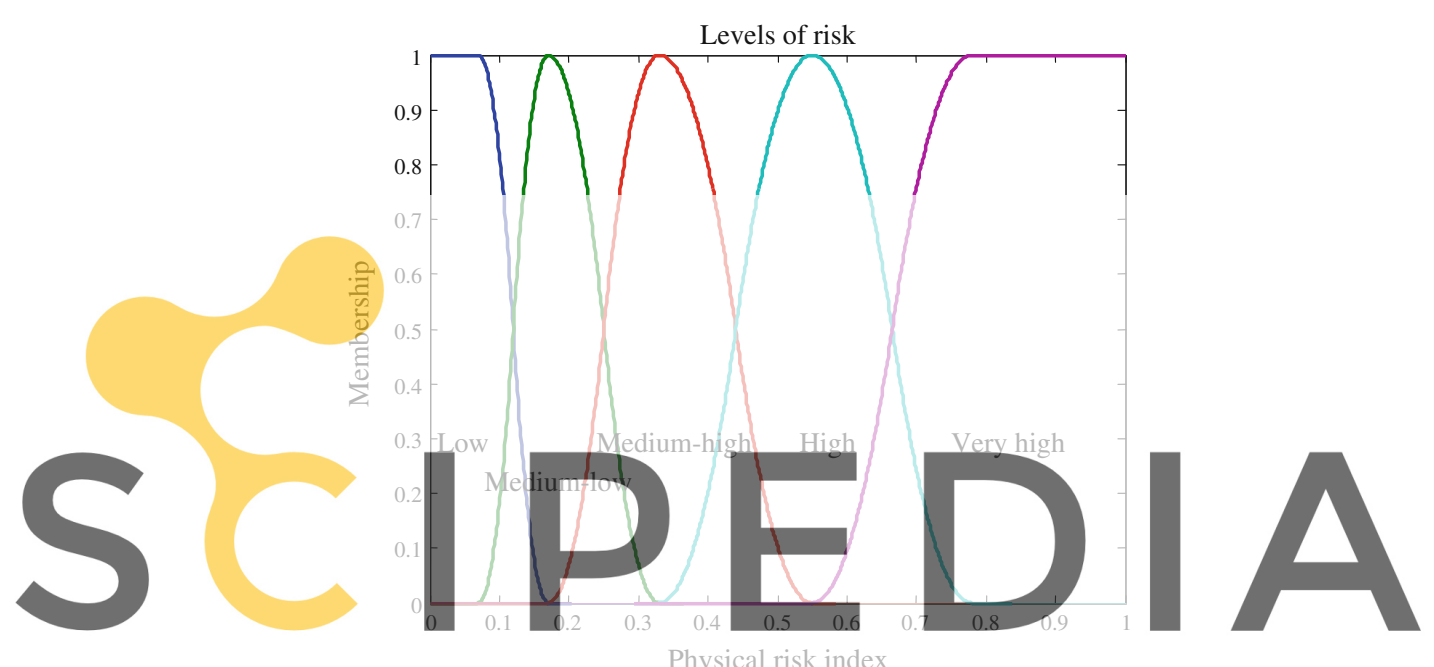

Register for free at https/(Www scipedia.com to download the version without the watermark

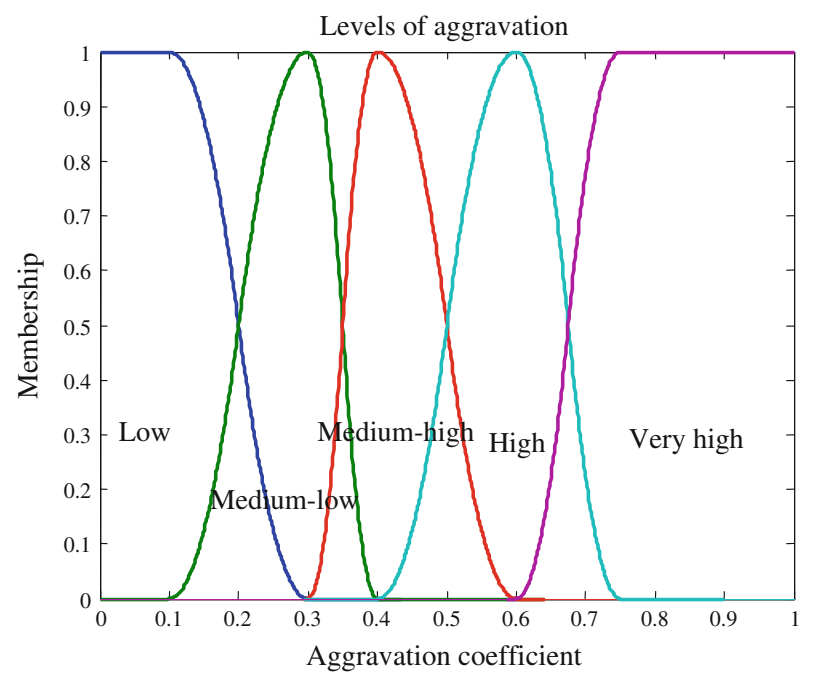

Fig. 9 Membership functions for levels of aggravation (Low, medium-low, medium-high, high and very high) 
This method has the advantage that in case of unavailable or incomplete information, the variables or indicators can be replaced by the opinion of local experts of the studied city.

The proposed methodology has been applied to the cities of Barcelona, Spain, and Bogotá, Colombia. The following section shows the obtained results.

\section{Case studies}

The case studies contain the results obtained by using the developed methodology for the cities of Barcelona, Spain, and Bogota, Colombia, whose results are also compared with those obtained with the original method based on indices.

\subsection{Barcelona, Spain}

The city of Barcelona, Spain, is subdivided in ten districts (see Fig. 10) which are subdivided in 38 traditional neighbourhoods and 248 small statistical zones (ZRP). The physical risk was calculated starting from a probabilistic risk scenario developed in the framework of the Risk-UE project of the European Commission (ICC/CIMNE 2004; Barbat et al. 1998, 2006, 2008, 2010; Lantada et al. 2009) considering the 248 ZRP. The aggravating coefficient was calculated by district, due to the availability of the required data only at this level.

Figure 11 shows the physical risk levels obtained for the 248 ZRP of Barcelona; most part of the city has a medium-low (142 ZRPs) and low (85 ZRPs) physical risk level; eight

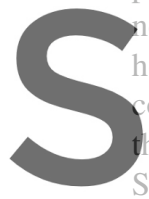

neighbourhoods have

hoods) has a high phy

oefficient and the correst

worst situation is

Sarria-Sant Gervasi.
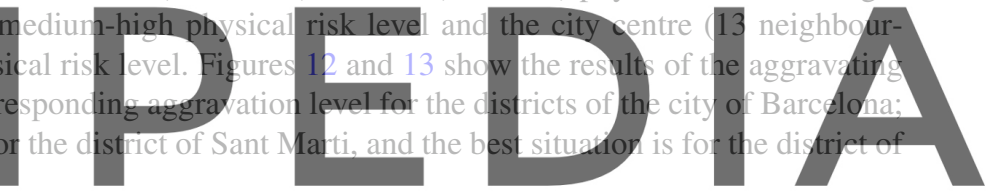

The total risk levels obtained are shown in Fig. 14, were most part of Barcelona (136 neigh-

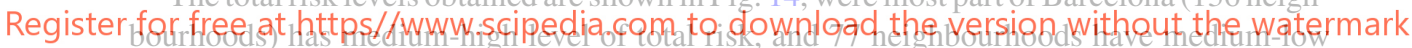
level of total risk.

In the case of Barcelona, when using the fuzzy sets methodology, the physical risk has higher levels but, inside the city, the risk level has more variability. This means that the

Fig. 10 Administrative territorial division of Barcelona

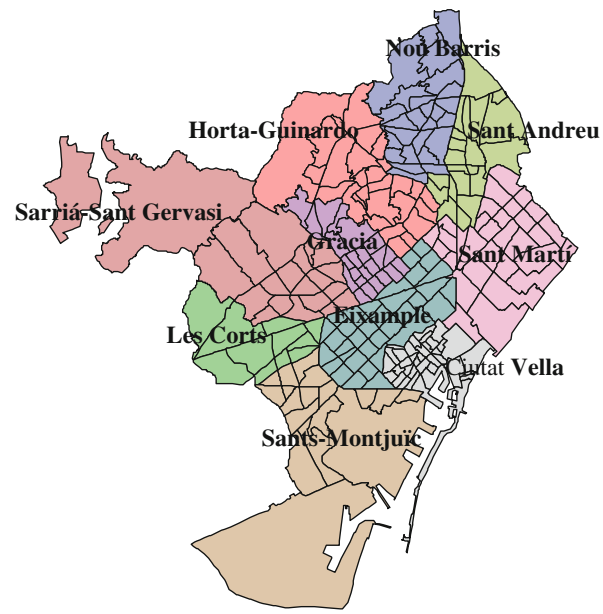


(a)

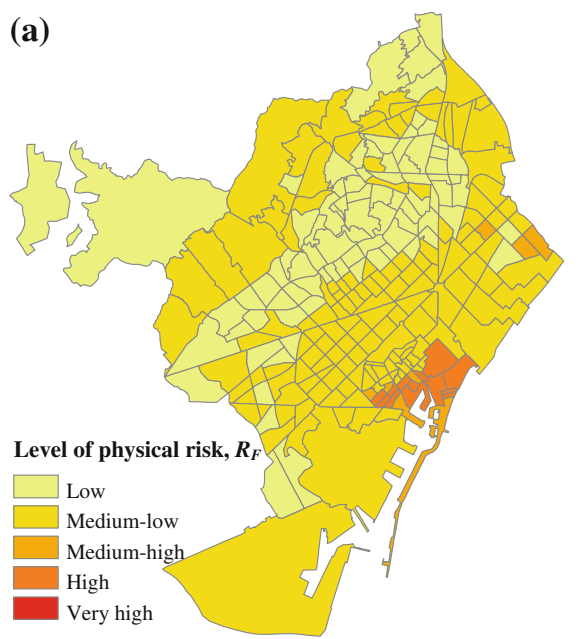

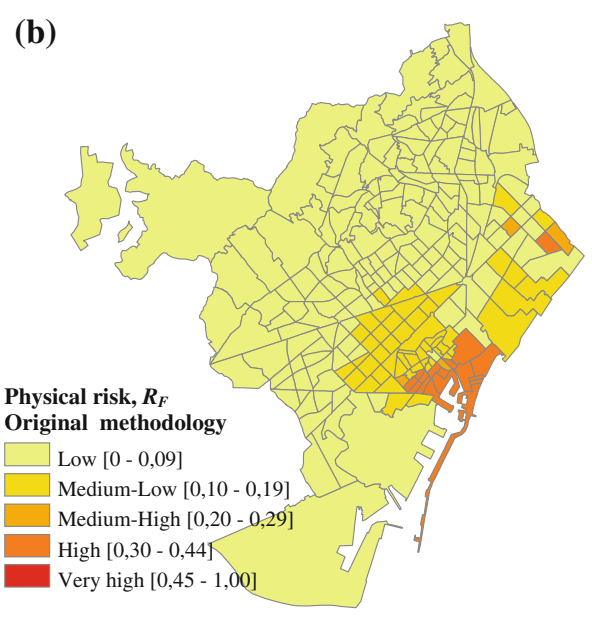

Fig. 11 Physical risk levels evaluated for Barcelona: a proposed methodology; $\mathbf{b}$ original methodology
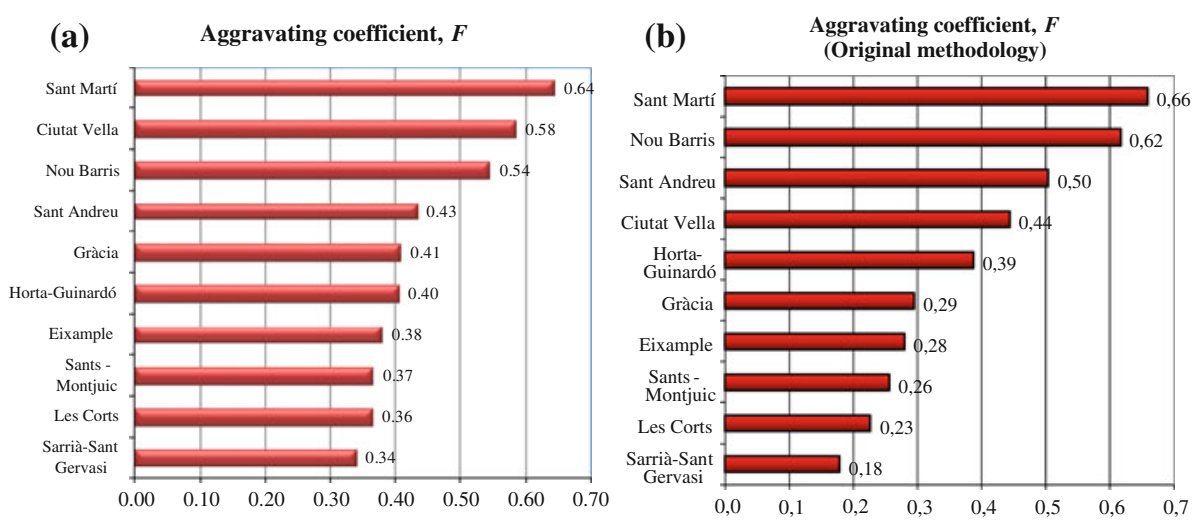

Fig. 12 Aggravating coefficient calculated for the Barcelona's districts: a proposed methodology; b original methodology

differences among neighbourhoods can be seen more clearly. The aggravating levels are in general one level greater than the results obtained with the original methodology, excepting the Sant Marti district which has one level lower than in the original case; and the districts of Sant Andreu and Nou Barris which have the same aggravating level than in the original case. The ranking of the districts according the aggravating coefficient is similar to that obtained with the original methodology. The total risk level has a similar trend than the physical risk outcomes; i.e., it has greater levels, but inside the city the risk levels have more variability.

Figures 15 and 16 show an example of the calculation process of the aggravating coefficient for the district of Sant Marti. Figure 15 shows the qualifications of the descriptors of social fragility and lack of resilience, affected by their correspondent weights while Fig. 16 shows their union and defuzzification. These figures allow identifying the aspects that have greater influence on the results what, in some cases, helps to guide and even prioritize measures to improve the socio-economic conditions in the area of study. As it can be 

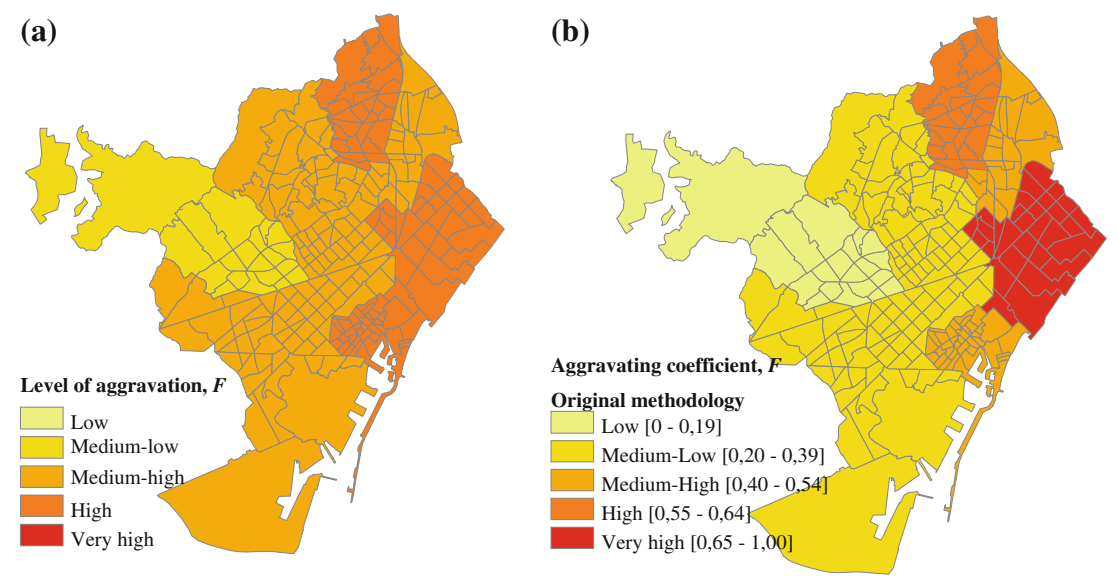

Fig. 13 Aggravation level calculated for the districts of Barcelona: a proposed methodology; $\mathbf{b}$ original methodology
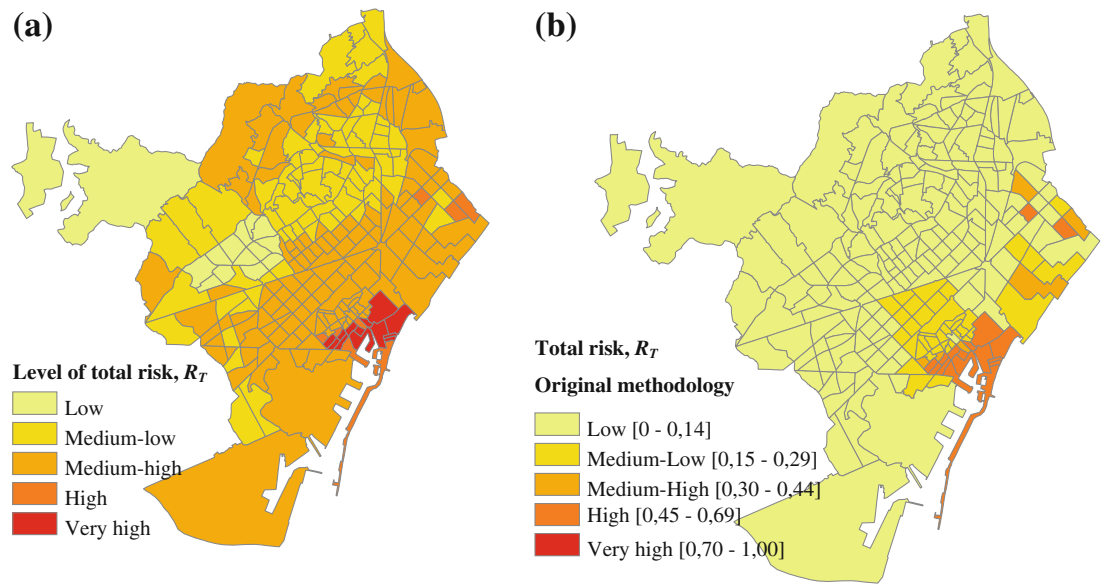

Fig. 14 Total risk levels evaluated for Barcelona: a proposed methodology; b original methodology

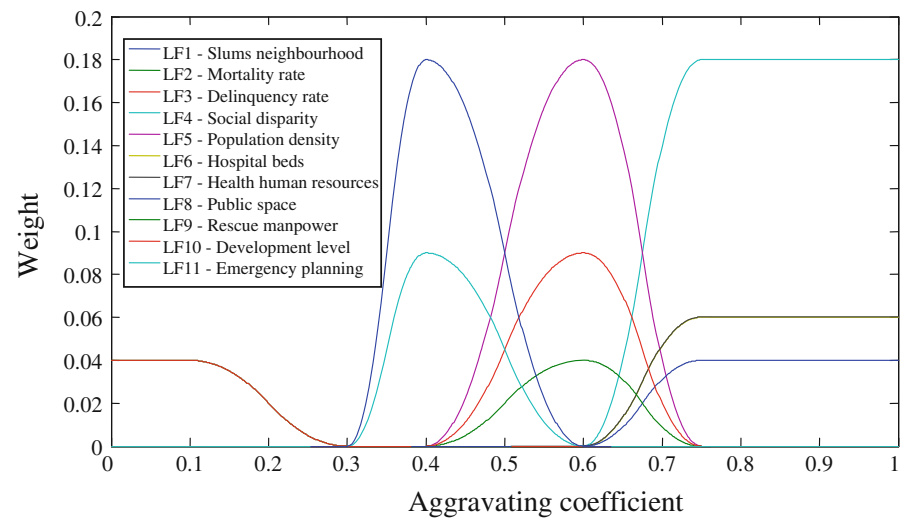

Fig. 15 Weighted membership functions of the aggravating coefficient for the Sant Marti district, Barcelona 


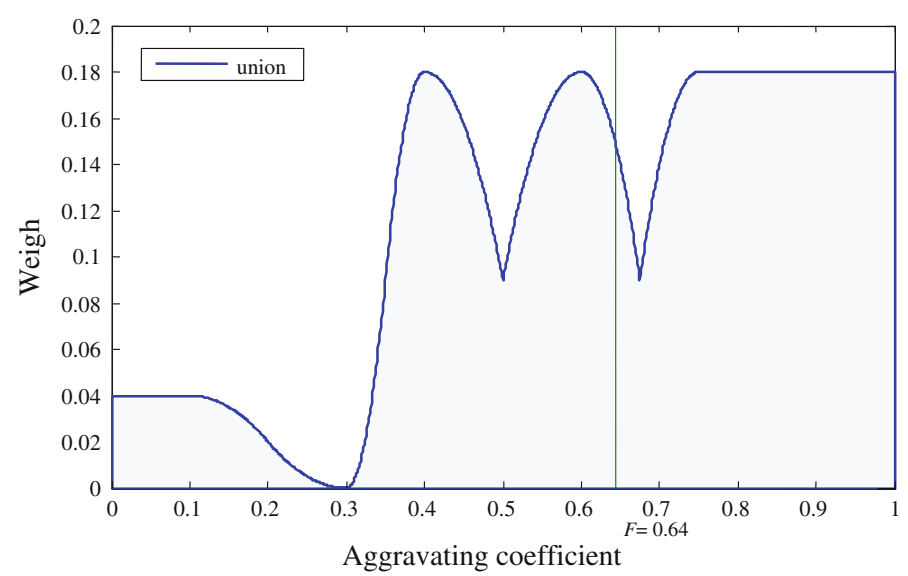

Fig. 16 Calculation of the aggravating coefficient, union and desfuzzification, for the district of Sant Marti, Barcelona

observed in Fig. 13, in the case of the Sant Marti district, the population density and the slum neighbourhood area are the most important factors.

\subsection{Bogota, Colombia}

In Bogota, the capital of Colombia, the localities are political-administrative divisions of the urban territory have clear competences in financing and application of the resources. They were created with the objective of attending in an effective way the needs of the population of each zone. Since 1992, Bogotá has 20 localities which can be seen in Fig. 17: Usaquén, Cha-

Fig. 17 Political-administrative division of Bogotá, Colombia

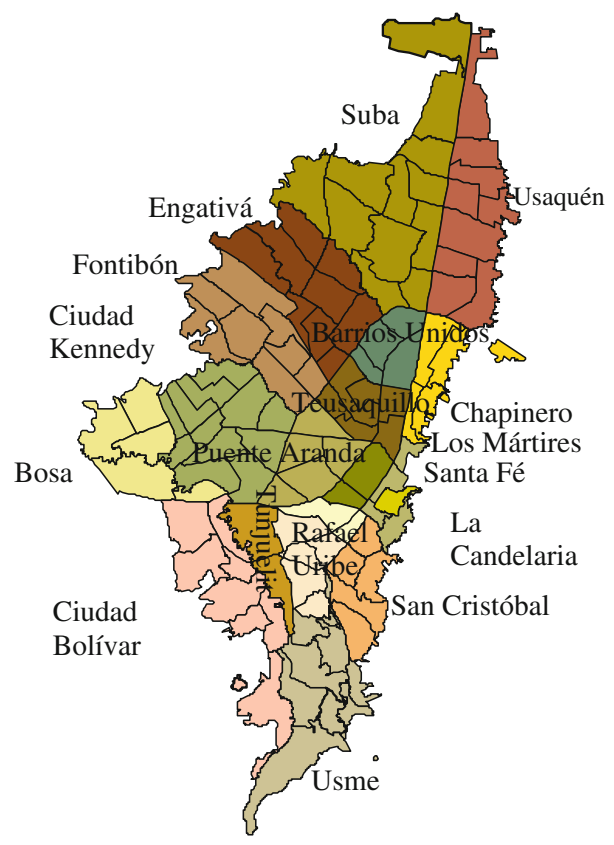



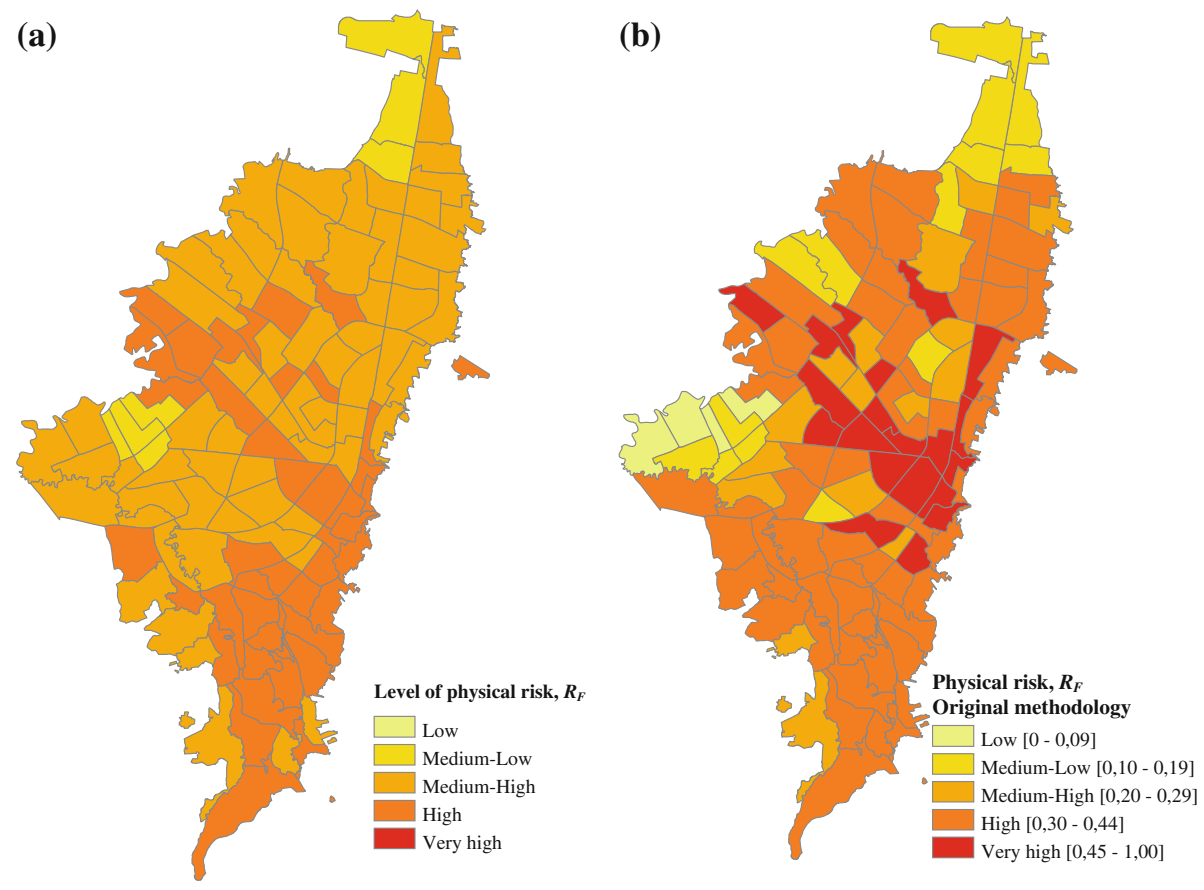

Fig. 18 Physical risk levels evaluated for Bogota: a proposed methodology; b original methodology


Fig. 19 Ranking of the aggravating coefficient calculated for Bogota's localities: a proposed methodology; b original methodology

pinero, Santafé, San Cristóbal, Usme, Tunjuelito, Bosa, Ciudad Kennedy, Fontibón, Engativa, Suba, Barrios Unidos, Teusaquillo, Mártires, Antonio Nariño, Puente Aranda, Candelaria, Rafael Uribe, Ciudad Bolívar y Sumapaz. In this study, only 19 of these localities are considered, because the locality of Sumapaz actually corresponds to the rural area of the city.

Figure 18 shows the physical risk levels obtained for the 117 UPZs (Units of Zone Planning) of Bogota calculated based on an existing damage scenario (Universidad de los Andes 

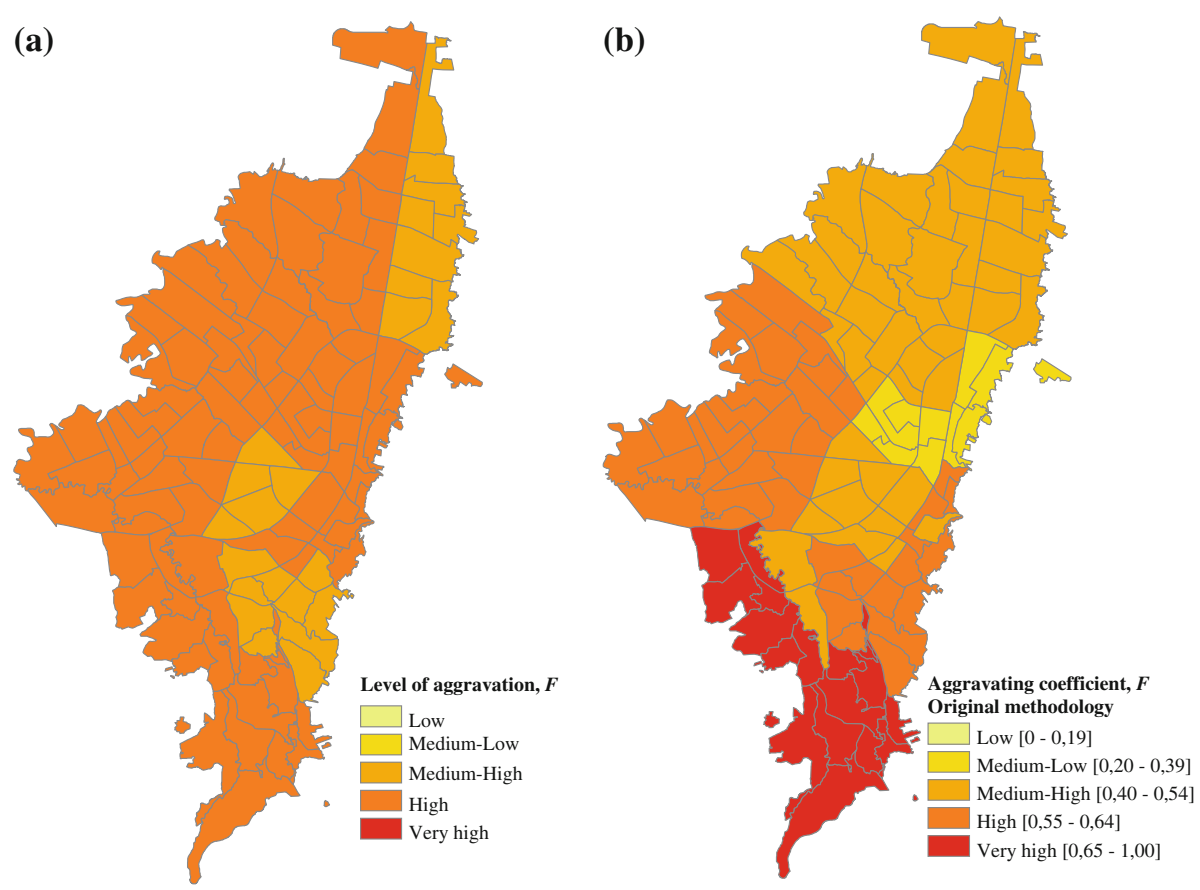

Fig. 20 Aggravating coefficient obtained for Bogota's localities: a proposed methodology; b original methodology
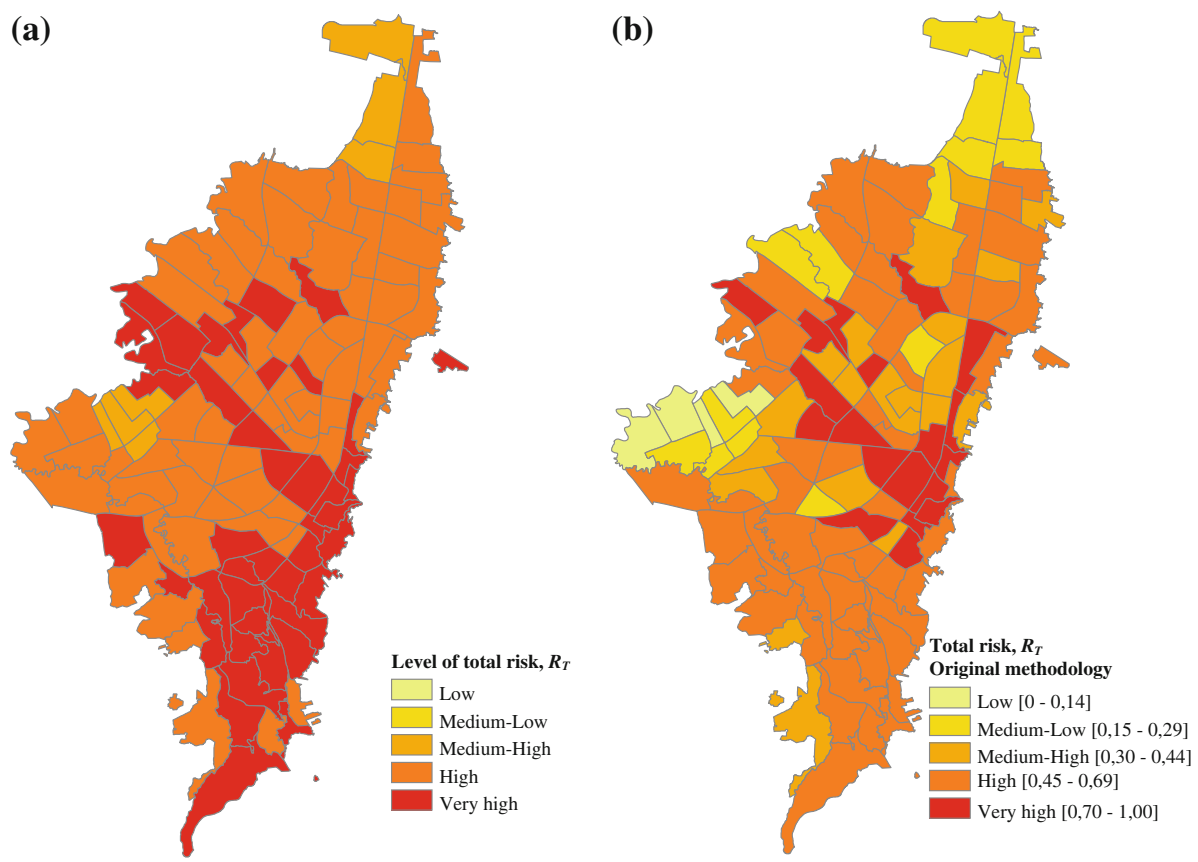

Fig. 21 Total risk levels calculated for Bogota: a proposed methodology; b original methodology 


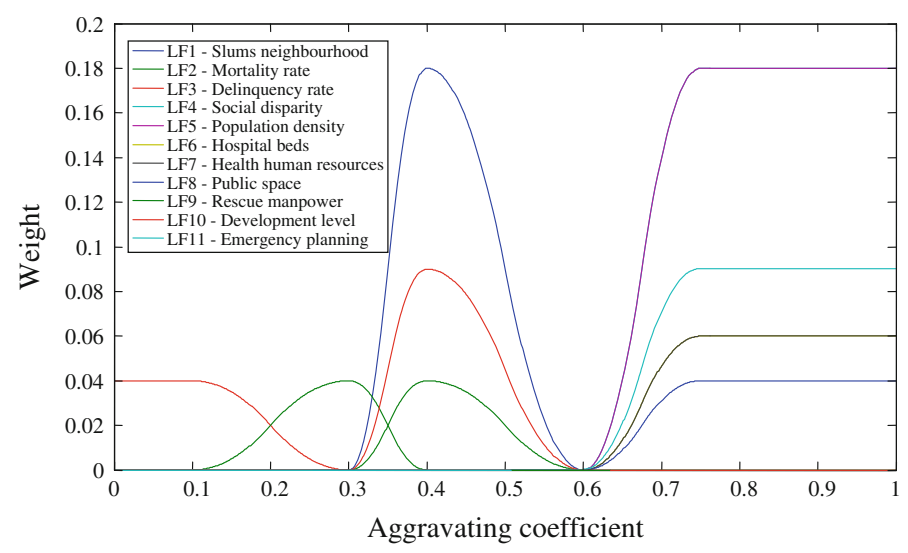

Fig. 22 Weighted membership functions of the aggravating coefficient for the locality of Ciudad Bolivar, Bogota

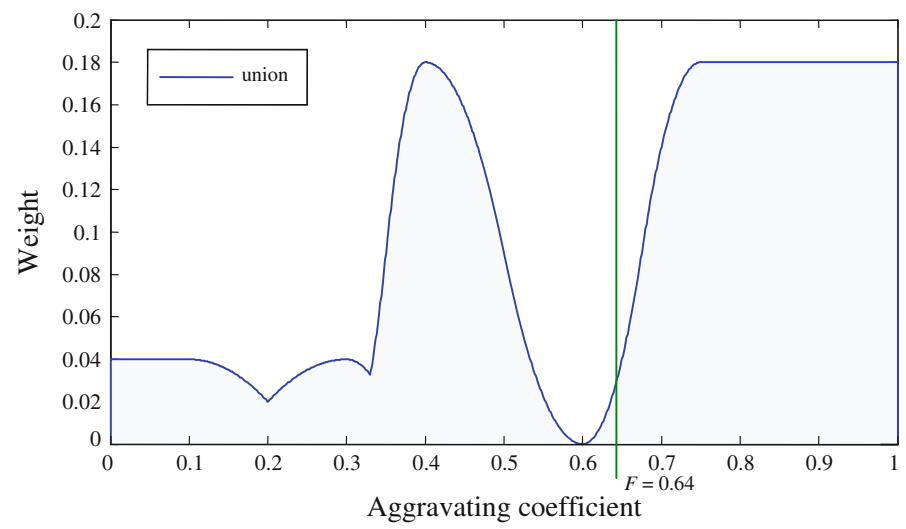

Fig. 23 Calculation of the aggravating coefficient, union and desfuzzification, for the locality of Ciudad Bolivar

2005); the most part of the city is distributed in three levels of physical risk: medium high (64 UPZs) and high (41 UPZs) physical risk. On the other hand, Figures 19 and 20 show the results for the aggravating coefficient of each locality of Bogota. It illustrates that most part of the city has high level of aggravation, the localities of Antonio Nariño, Chapinero, Usaquen and Teusaquillo have medium-high aggravation level. Figure 21 shows the results of the total risk; it shows that most part of the city (64 UPZs) has high level and 41 UPZs have very high level of total risk.

In the case of Bogota, some of the results obtained with the fuzzy sets methodology for physical risk have one greater level of risk than those obtained with the results of the original methodology, but this is not the general trend. The ranking of the localities according the aggravating coefficient is similar to that obtained with the original methodology. The total risk has higher values and levels.

Figures 22 and 23 show an example of the calculation process of the aggravating coefficient for the locality of Ciudad Bolivar. Figure 22 shows the qualifications of the descriptors of social fragility and lack of resilience affected by their correspondent weights and Fig. 23 
shows their union and defuzzification. These figures allow identifying the aspects that have the greatest influence on the results. In the case of Ciudad Bolivar, the population density and the social disparity are the most important factors; both involve a very high aggravation level. Although the factors of emergency planning, health human resources, public space and hospital beds are not the dominant factors in this case, each of these indicators involves a very high aggravation level.

\section{Conclusions}

A simplified but multidisciplinary model of the urban seismic risk has been proposed in this paper, based on the parametric use of variables that reflect different aspects of such risk. This model is formulated in the most realistic possible manner, using fuzzy sets, in such a way that corrections or alternative figures may be continuously introduced. The consideration of physical aspects allowed the construction of a physical risk index. In addition, the contextual variables (social, economic, etc.) allowed the construction of an aggravation coefficient. The former is built from the information about the seismic scenarios of physical damage (direct effects) and the latter is the result of estimating the aggravating conditions (indirect effects) based on descriptors and factors related to the social fragility and the lack of resilience of the exposed elements. The proposed application of fuzzy sets is especially useful for those cases in which the necessary information is not available, and thus, it can be replaced by experts' opinion.

This new fuzzy model for holistic evaluation of risk facilitates the integrated risk management by the different stakeholders involved in risk reduction decision-making. The proposed method has been applied to the cities of Barcelona (Spain) and Bogota (Colombia), proved to be robust, and allowed to identify the most relevant aspects of the total risk index, with no need for further analysis and interpretation of results.

From the results is possible to conclude in general that the physical risk is higher in Bogotá than in Barcelona, what reflects the medium-high seismic hazard in the case of Bogotá and the medium-low seismic hazard of Barcelona. The aggravation level of Barcelona is, in average, one level lower than in Bogotá. And lastly, the total risk level of Bogotá is notably higher than the total risk level of Barcelona.

The case studies clarify how the evaluation process of the aggravating coefficient is performed. These figures allow identifying those aspects which have a determinant influence on the results and this exercise is useful for guiding and even prioritize measures to improve the socio-economic conditions in the area of study. The same weights in both case studies have been used and the aggravation coefficient value is the same in both cases but due to different reasons. In both cases the dominant factor is the social disparity. In the case of Ciudad Bolivar (Bogotá), the population density is dominant in the same way, indicators as emergency planning, health human resources, public space and hospital beds involves a very high level of aggravation, but they are not dominant in the evaluation. In the case of Sant Marti (Barcelona), the population density is also an important factor, but in this case it involves a high aggravation level, the slum neighbourhood area involves a medium aggravation level.

This paper does not include the robustness evaluation of the proposed methodology, but this kind of analysis was already performed in a previous article (Marulanda et al. 2009) for the original methodology based on indicators. This analysis can be performed in future works and it could modify the weights of the variables and the shape of the membership functions. The influence of this variation of the membership functions on the results will be probable 
not important because the membership functions are based on the transformation functions of the original methodology.

Acknowledgments This work has been partially sponsored by the Universities and Research Commissionate of the Generalitat de Catalunya (Beatriu de Pinos grants proggrame) and by the Spanish Ministry of Education and Science (SEDUREC, CONSOLIDER CSD2006-00060) by the European Commission (project Methods for the Improvement of Vulnerability Assessment in Europe, MOVE, FP7-ENV-2007-1-211590) and INTERREG: POCTEFA 2007-2013/ 73/08.

\section{References}

Barbat AH, Cardona OD (2003) Vulnerability and disaster risk indices from engineering perspective and holistic approach to consider hard and soft variables at urban level. IDB/IDEA Program on Indicators for Disaster Risk Management, http://idea.unalmzl.edu.co. Universidad Nacional de Colombia, Manizales

Barbat AH, Mena U, Yépez F (1998) Evaluación probabilista del riesgo sísmico en zonas urbanas. Revista internacional de métodos numéricos para cálculo y diseño en ingeniería 14(2):247-268

Barbat AH, Pujades LG, Lantada N, Moreno R (2006) Performance of buildings under earthquakes in Barcelona Spain. Comput Aided Civil Infrastruct Eng 21:573-593

Barbat AH, Pujades LG, Lantada N, Moreno R (2008) Seismic damage evaluation in urban areas using the capacity spectrum method: application to Barcelona. Soil Dyn Earthq Eng 28:851-865

Barbat AH, Carreño ML, Pujades LG, Lantada N, Cardona OD, Marulanda MC (2010) Seismic vulnerability and risk evaluation methods for urban areas. A review with application to a pilot area. Struct Infrastruct Eng 6(1-2):17-38

Barbat AH, Carreño ML, Cardona OD, Marulanda MC (2011) Evaluación holística del riesgo sísmico en zonas urbanas, Revista Internacional de Métodos Numéricos para Cálculo y Diseño en Ingeniería 27:3-27

Cardona OD (2001) Holistic evaluation of the seismic risk using complex dynamic systems (in Spanish). PhD Thesis, Technical University of Catalonia, Barcelona, Spain

Cardona OD (2004) The need for rethinking the concepts of vulnerability and risk from a holistic perspective: a necessary review and criticism for effective risk management. In: Bankoff G, Frerks G, Hilhorst D (eds) Mapping vulnerability: disasters, development and people. Earthscan Publishers, London

Cardona OD (2009) Disaster risk and vulnerability: notions and measurement of human and environmental insecurity. In: Brauch HG, Oswald Spring U, Mesjasz C, Grin J, Kameri-Mbote P, Chourou B, Dunay P, Birkmann J (eds) Coping with global environmental change, disasters and security-threats, challenges, vulnerabilities and risks. Springer, Berlin.

Cardona OD, Hurtado JE (2000) Holistic seismic risk estimation of a metropolitan center. In: Proceedings of 12th world conference of earthquake engineering, Auckland, New Zeland

Cardona OD, Barbat AH (2000) El Riesgo Sísmico y su Prevención, Cuaderno Técnico 5, Calidad Siderúrgica, Madrid

Cardona OD, Hurtado JE, Duque G, Moreno A, Chardon AC, Velásquez LS, Prieto SD (2003) Indicators for risk measurement: methodological fundamentals, BID/IDEA Programa de Indicadores para la Gestión de Riesgos, Universidad Nacional de Colombia, Manizales. http://idea.unalmzl.edu.co.

Carreño ML (2006) Técnicas innovadoras para la evaluación del riego sísmico y su gestión en centros urbanos: Acciones ex ante y ex post. PhD Thesis, Technical University of Catalonia, Barcelona, Spain, Departamento de Ingeniería del Terreno, cartografía y geofísica

Carreño ML, Cardona OD, Barbat AH (2007) Urban seismic risk evaluation: a holistic approach. Nat Hazards 40(1):132-137

Carreño ML, Cardona OD, Barbat AH (2007) Disaster risk management performance index. Nat Hazards 41:1-20

ICC/CIMNE (2004) An advanced approach to earthquake risk scenarios with applications to different european towns, WP08, Application to Barcelona, RISK-UE Project

IDEA (2005) System of indicators for disaster risk management: main technical report. IDB/IDEA Programme of Indicators for Disaster Risk Management, Universidad Nacional de Colombia, Manizales

Lantada N, Pujades LG, Barbat AH (2009) Vulnerability index and capacity spectrum based methods for urban seismic risk evaluation. A comparison. Nat Hazards 51:501-524

Marulanda MC, Cardona OD, Barbat AH (2009) Robustness of the holistic seismic risk evaluation in urban centers using the USRi. Nat Hazards 49:501-516 
Masure P (2003) Variables and indicators of vulnerability and disaster risk for land-use and urban or territorial planning. IDB/IDEA Programa de Indicadores para la Gestión de Riesgos, http://idea.unalmzl.edu.co, Universidad Nacional de Colombia, Manizales

Saaty TL, Vargas LG (1991) Prediction, projection, and forecasting: applications of the analytical hierarchy process in economics, finance, politics, games, and sports. Kluwer, Boston

UNDRO (1980) Natural disasters and vulnerability analysis. Report of Experts Group Meeting, UNDRO, Geneva

Universidad de los Andes (2005) Escenarios de riesgo y pérdidas por terremoto para Bogota, D.C, Centro de Estudios sobre Desastres y Riesgos CEDERI, Alcaldía Mayor de Bogotá, Dirección de Prevención y Atención de Emergencias, DPAE, Bogota, Colombia, 2005 